\title{
La intermediación turística en España y su vinculación con el Marketing de Afiliación: una aproximación a la realidad de las Agencias de Viajes
}

\author{
Clide Rodríguez Vázquez* $M^{\mathrm{a}}$ Magdalena Rodríguez Fernández** \\ Valentín Alejandro Martínez Fernández**** \\ Oscar Juanatey Boga**** \\ Universidad de A Coruña (España)
}

\begin{abstract}
Resumen: En el ámbito de la intermediación turística en España, la coyuntura económica, social y tecnológica desempeña un papel determinante en su desarrollo, lo que demanda la aplicación de nuevas estrategias de comercialización como es el caso, entre otras, del marketing de afiliación.

El objetivo de este artículo se fundamenta en analizar la relación existente entre las agencias de viajes españolas y el marketing de afiliación como herramienta online. Dadas las características propias del estudio, la revisión de la literatura aconsejó, como más pertinente, el diseño e implementación de una metodología de carácter cualitativo orientada a la obtención y análisis de información primaria que, a su vez, permitiese ser complementada por fuentes secundarias; en este sentido se optó por la realización de entrevistas en profundidad, de carácter abierto, a expertos relevantes en el tema objeto de estudio.

El desarrollo de dicha metodología ha permitido contrastar las pertinentes hipótesis, surgidas del previo marco configurador del estado del arte y, por consiguiente, la extracción de las correspondientes conclusiones.

Palabras Clave: Intermediación turística, agencias tradicionales u offline, agencias online, marketing de afiliación, estrategia, comercialización, publicidad.
\end{abstract}

The tourism intermediation in Spain and its relationship with Affiliate Marketing: an approach to the reality of Travel Agencies

Abstract: In the area tourist intermediation in Spain, the economic, social and technological conjuncture is playing an important role in its development, which requires the implementation of new strategies of commercialization as the affiliate marketing.

The aim of this paper is based on analyzing the relationship between Spanish travel agencies and the affiliate as tool online. Owing to the specific features of the study, a review of the literature showed as more appropriate the design and implementation of a qualitative methodology, focused on getting and analyzing the primary data, which could be supplemented by other secondary sources. Regarding this, in-depth and open-ended interviews to relevant experts in the field of the study were taken.

The development of such methodology allows the contrast of the pertinent hypothesis that became from the previous frame of the state of art and, therefore the extraction of their conclusions.

Keywords: tourism intermediation, traditional agencies or offline, agencies online, affiliate marketing, strategy, commercialization, advertising.

\footnotetext{
* E-mail: crodriguezv@udc.es

* E-mail: mmrodriguez@udc.es

**** E-mail: valejand@udc.es

**** E-mail: . oscarjb@udc.es
} 


\section{Introducción}

El contexto económico y social que describe al entorno empresarial, posibilita que la toma de decisiones por parte de las organizaciones se encamine al diseño y aplicación de estrategias cuyo objetivo prioritario se focalice en captar a aquellos consumidores con poder y criterio de decisión; así como en convencer a los disconformes, a través de informaciones que generen valor y les aporten confianza. El objetivo principal es fidelizar a los clientes.

En este sentido, Internet ha supuesto para el marketing empresarial nuevos retos, no sólo por la aportación de nuevas herramientas para la captación y fidelización de clientes, sino también por permitir un mayor contacto y conocimiento, para atender las necesidades y demandas del consumidor y lograr, incluso, una cierta interactuación entre los diferentes agentes que intervienen en el proceso de comercialización.

Ante este escenario, los intermediarios turísticos ${ }^{1}$ en general y en concreto las agencias de viajes están experimentando importantes cambios. El subsector de los viajes tradicionales se enfrenta a situaciones de incertidumbre, afectadas principalmente por la coyuntura económica actual, así como por la incursión de las Tecnologías de la Información y Comunicación (TICs). Las TICs han posibilitado la aparición y el crecimiento de las agencias online, al haber sido capaces de adaptar la oferta de servicios turísticos a los cambios tecnológicos y a la demanda actual al ofrecer nuevas oportunidades a los consumidores para disfrutar de los mismos productos a precios más competitivos y reportarles idéntica o similar satisfacción.

Tal y como señala Fraiz et al (2012), en el universo de las TICs todo ocurre a una velocidad de vértigo. Las relaciones entre las agencias y el cliente han variado notablemente, de modo que los procesos de distribución y de acceso a las reservas se han vuelto más dinámicos. En el caso de las agencias online, se han desplazado los lugares físicos y se han sustituido por espacios virtuales en los que el contacto personal se ha restringido enormemente siendo reconducido a través de la red, lo cual ha derivado en mejoras de costes, rapidez y eficiencia sin menoscabar la atención personalizada que se realiza.

A finales de la década pasada y, según el Estudio General de Internet ${ }^{2}$ (EGI, 2006) más de la mitad de las compras que se realizaron en España a través de la red correspondieron a viajes, se puede por tanto observar cómo las agencias virtuales han encontrado una nueva fórmula de negocio y orientación al mercado.

En el caso de las agencias tradicionales u offline se aprecia un importante descenso en relación al número de puntos de venta. De las 9.127 agencias IATA ${ }^{3}$ que configuraban el panorama en el año 2007 se pasó a 8.689 en el año 2008, lo que supuso un descenso del 4,8\%; en el año 2009 el número descendió a 7.500, hasta llegar a los 5.881 puntos de venta del $2011^{4}$, lo cual representaba un $22 \%$ menos o lo que es lo mismo, 1.556 agencias menos (De la Rosa, 2011).

La relevancia de estos datos incide también de forma directa, en el descenso del número de empleados de estas agencias. Según datos difundidos por el Ministerio de Trabajo e Inmigración (2012), en diciembre de 2011 el número de trabajadores ascendía a 52.920, lo que representaba un descenso del 2,3\% en relación a 2010. Un año antes, en 2009, estas empresas habían dado empleo a 53.929 profesionales asalariados.

Conforme a los datos citados, la situación del sector travel en España atraviesa por momentos difíciles, tanto en relación al descenso en el número de agencias offline, al personal empleado por ellas, así como a la importancia que, cada vez más, acaparan las agencias online.

Todos estos cambios propician que intermediarios turísticos como las agencias de viajes, se vean abocadas a plantear estrategias para competir eficientemente en los momentos de crisis; surge así la posibilidad de aplicar una nueva herramienta: el marketing de afiliación. Modelo capaz de ofrecer oportunidades para que dichas empresas puedan sobrevivir y enfrentarse a los entornos cambiantes, a través de la realización de una publicidad online dirigida a un segmento de demanda determinado, capaz de posibilitar un ahorro en los costes y revertir positivamente en la obtención de beneficios.

\section{Estado de la cuestión}

La creación de nuevos modelos de comunicación, en los que el marketing online ha desempeñado un papel relevante, así como el desarrollo de las Tecnologías de la Información y Comunicación (TICs), han sido hechos ciertamente significativos para el sector turístico en la última década, al propiciar un determinado cambio de paradigma en la comercialización y en la promoción de productos turísticos. 
Numerosos autores analizan este cambio en sus respectivas investigaciones Werthner y Klein (1999); Rastrollo y Alarcón (2000); Doolin, Burgess y Cooper (2002) y coinciden en indicar que las tecnologías de la información no sólo reducen costes, sino que incrementan la eficacia operativa de las organizaciones que las emplean y desarrollan un importante papel en la venta, comercialización y comunicación en el sector turístico.

Sin embargo, en el ámbito académico, el marketing de afiliación, como disciplina emergente en la última década y motivo de análisis de este artículo junto con el subsector de las agencias de viajes, todavía no ha sido objeto de una relevante atención por parte de los investigadores en marketing, cuestión que se refleja en escasas aportaciones al ámbito científico. La revisión de la literatura muestra que, de momento, son muy pocas las publicaciones académicas en cuyos respectivos números aparecen trabajos relacionados, directa o indirectamente, con esta nueva modalidad del marketing. Ante esta evidencia y de acuerdo con Kirkpatrick y Locke (1992), puede considerarse que si las publicaciones en revistas académicas de prestigio se utilizan, generalmente, como evidencia de la actividad investigadora en una rama, se puede concluir que esta disciplina está en una etapa incipiente de su desarrollo científico. En el mismo sentido, Jafari (2005) señala la importancia que las publicaciones científicas tienen en los distintos campos a la hora de reconocer el valor, implantación y aceptación por la comunidad académica de una nueva disciplina o temática dimanante de ésta.

En lo que respecta a la revisión de la abundante literatura existente sobre turismo, son significativas algunas obras de diferentes autores que permiten tener una visión más próxima del sector turístico, desde su origen e importancia como actividad económica, con la finalidad de comprender de qué modo se gestionan las empresas turísticas, especialmente las agencias de viaje, así como las tendencias futuras del sector, atendiendo principalmente a la diferenciación y competitividad que puede aportarles las nuevas tecnologías, entre ellos cabe citar a: Buhalis (1995); Wardell (1998); Vellas y Becherel (1999); Suárez, Vázquez y Díaz (2004).

Por otro lado, siendo conscientes de que las agencias de viajes son el principal agente de intermediación turística del mundo (Middelton, 1997), y de la importancia de éstas en la distribución turística, se observa una escasa atención sobre dicha temática por parte de los investigadores tal y cómo señalan Bitner y Booms (1982); Booms y Kendall (1989) y Goeldner y Ritchie (2009).

No obstante, en el contexto de las agencias de viajes en España, existen trabajos científicos que analizan la importancia de generar valor al cliente para fidelizarle, al entender que lo importante es disponer de una ventaja competitiva, que contribuya a diferenciar a la organización (López, 2001; Sousa, 2003; Esteban, 2003 y Suárez, 2004) y satisfacer al cliente (Millán, 2001, Suarez et al, 2007 y Guijarro, 2010).

Otras investigaciones dirigen la atención hacia Internet como el futuro de la intermediación turística, analizando la respuesta que ofrecen las agencias de viajes a los importantes cambios que introduce la sociedad de la información (Albert, 2006; Andreu, 2009; Berné et al, 2011). Del mismo modo Alza (2004); Garrido (2010) y Galhanone et al (2010), realizan un análisis del perfil del internauta, incidiendo en las posibilidades que ofrece este canal como plataforma para la comercialización de los productos turísticos y la satisfacción de las necesidades.

\section{La intermediación turística en España desde la perspectiva de las agencias de viajes}

Desde que comenzó la crisis económica en España han cerrado más de 4.000 agencias de viajes tradicionales, y ello ha afectado a una cuarta parte del sector.

El análisis histórico del mercado español, centrado en las agencias de viajes, muestra como rasgo característico la sobredimensión en la oferta, de modo que la disminución en el volumen de negocio de estas empresas ha contribuido a subsanar de algún modo este problema, en detrimento de las agencias pequeñas, que se han visto especialmente afectadas.

Desde el tercer trimestre de 2007, se aprecia una contracción en las ventas de viajes hacia destinos españoles, lo cual ha incidido significativamente en un gran número de agencias de viajes minoristas y mayoristas de nuestro país, tal y como se desprende de los datos publicados por el Ministerio de Industria, Turismo y Comercio de España a través del Instituto de Estudios Turísticos (2008, 2009, 2010 y 2011). Ahora bien, el crecimiento de los viajes en el mercado internacional con mayores márgenes empresariales y la leve alza de los precios, han neutralizado el efecto del retroceso en el crecimiento de las ventas y posibilitado así una cierta estabilización en cuanto al incremento interanual de los beneficios en el tercer trimestre de 2007. 
El turbulento escenario económico acaecido desde el año 2008, ha provocado un descenso de la demanda turística, lo cual ha generado que los grupos turísticos españoles más importantes lleven a cabo importantes esfuerzos para reducir los costes, y mantener así el nivel de beneficios de 2008 tanto en: el sector minorista y mayorista, como en los grupos turísticos empresariales y comerciales.

En este sentido, la aplicación de las Tecnologías de la Información y Comunicación (TICs) en las últimas décadas, ha afectado al entorno competitivo, con especial repercusión para la industria turística en general y para las agencias de viajes en particular (Sheldon et al, 2001).

La irrupción en el mercado de canales de comunicación, comercialización y distribución como Internet, ha posibilitado poner al alcance de las organizaciones y del consumidor turístico poderosas redes y tecnologías, asistiendo de este modo al nacimiento de nuevos conceptos y modelos de gestión en el contexto turístico. Internet se ha convertido, por tanto, para las empresas de intermediación turística, en un escaparate virtual informativo y comercial de ámbito internacional, al representar un complemento a la faceta presencial que tradicionalmente realizan.

Todos los cambios económicos, sociales y tecnológicos que se ciernen sobre el entorno actual, llevan al sector de la intermediación turística a replantearse soluciones para sobrevivir y mantenerse en el mercado. Entre las mismas se encuentran (Hosteltur, 2012):

- La internacionalización y las alianzas en el ámbito turístico-empresarial.

- Una nueva filosofía de precios.

- La concentración sectorial del propio subsector de los viajes.

- La especialización.

En virtud del panorama descrito y antes de analizar la situación del sector travel en España, es importante destacar los tipos de agencias que operan en el mercado español y cuáles son las normativas a las que están sujetas.

En relación a la normativa vigente, debe hacerse referencia al Real Decreto 271/1988, de 25 de marzo, por el cual se regula el ejercicio de las actividades propias de las agencias de viajes $\left(\mathrm{BOE}^{\circ} 76\right.$, 29 de marzo 1988). Así, tienen la consideración de agencias de viajes las empresas que, en posesión del título-licencia correspondiente, se dedican profesional y comercialmente en exclusividad al ejercicio de actividades de mediación y/u organización de servicios turísticos, pudiendo utilizar medios propios en la prestación de los mismos.

La condición legal y la denominación de agencias de viajes quedan reservadas exclusivamente a las empresas a que se refiere el apartado anterior. Los términos "viaje" o "viajes" sólo podrán utilizarse como todo o parte del título o subtítulo que rotule sus actividades, por quienes tengan la condición legal de agencias de viajes.

Son por tanto objeto o fines propios de las agencias de viajes los siguientes:

- La mediación en la venta de billetes o reserva de plazas en toda clase de medios de transporte, así como en la reserva de habitaciones y servicios en las empresas turísticas.

- La organización y venta de los denominados paquetes turísticos o viajes combinados.

- La actuación como representantes de otras agencias nacionales o extranjeras para la prestación, en su nombre y a la clientela de éstas, de los servicios que constituyen objeto propio de su actividad.

- Cualquier otro servicio que se reconozcan como propios de su actividad de acuerdo con la legislación vigente.

El ejercicio de las actividades a que se refiere el párrafo anterior estará exclusivamente reservado a las agencias de viajes, sin perjuicio de la facultad conferida por la legislación vigente a transportistas, hoteleros y otras empresas turísticas para contratar directamente con los clientes la prestación de sus propios servicios.

En lo referente a las tipologías, las agencias de viajes en España pueden ser de tres tipos: Mayoristas, Minoristas y Mayoristas-Minoristas:

- Son Agencias Mayoristas aquellas que proyectan, elaboran y organizan toda clase de servicios y paquetes turísticos para su ofrecimiento a las agencias minoristas, no pudiendo ofrecer sus productos directamente al usuario o consumidor.

- Son Agencias Minoristas aquellas que, o bien comercializan el producto de las agencias mayoristas, proporcionándolo directamente al usuario o consumidor, o bien proyectan, elaboran, organizan y/o suministran toda clase de servicios y paquetes turísticos directamente al usuario, no pudiendo ofrecer sus productos a otras agencias.

- Son Agencias Mayoristas-Minoristas aquellas que pueden simultanear las actividades mencionadas en los dos apartados anteriores. 
Es conveniente señalar aquí otras dos leyes que atañen directamente al desarrollo propio de las actividades de las agencias de viajes en España. Por un lado, la Ley 21/95, de 6 de julio, de Viajes Combinados, modificada por la Ley $39 / 2002^{5}$ que pone de manifiesto dos aspectos fundamentales: la necesidad de unificar criterios en el ámbito de la CEE, y el reconocimiento de los derechos y obligaciones de los clientes de las agencias de viajes como consumidores.

Por otro lado, la Directiva 2006/123/CE del Parlamento Europeo y del Consejo del 12 de diciembre de 2006, más conocida como Directiva Bolkestein, relativa a los servicios en el mercado interior, establece que quedan excluidos de su campo de aplicación los servicios de transporte, e incluidos en general los demás relacionados con el turismo. El texto cita expresamente los servicios de organización de ferias, el alquiler de vehículos y las agencias de viajes, los guías turísticos, los servicios recreativos, los centros deportivos y los parques de atracciones.

\section{Situación de las principales empresas del sector travel que operan en España}

Después de abordar, desde una perspectiva teórica, las diferentes tipologías existentes en el sector travel español, así como la normativa aplicable al mismo, a continuación se analiza la situación de las agencias de viajes: minoristas, mayoristas y online.

\section{Agencias minoristas}

Según el último ranking publicado por NEXOTUR de agencias de viajes minoristas, las diez grandes redes que operaban en el mercado español habían finalizado 2011 con una facturación conjunta de $6.612,6 \mathrm{M} €$, un $6,5 \%$ más que en 2010 cuando sus ventas se situaron en $6.208,8$ millones.

Viajes El Corte Inglés mantenía su posición de liderazgo, al superar en más de $1.000 \mathrm{M} €$ a su más inmediato seguidor, Halcón Viajes Ecuador. La red de agencias Viajes El Corte Inglés había finalizado 2011 con $2.428 \mathrm{M} €$, un $6 \%$ más que en 2010.

En segundo lugar aparece Halcón Viajes Ecuador ${ }^{6}$, que concluyó el año con una facturación de 1.374 $\mathrm{M} €$, un 4,4\% más que en 2010. La empresa incrementó su participación gracias al aumento del número de franquicias.

En 2011 Viajes Iberia se mantenía en tercera posición, a la que ascendió en 2010 tras el cierre de Viajes Marsans. La red minorista de la desaparecida Orizonia que, al igual que otras divisiones del grupo, era objeto de una profunda transformación (cambiando su denominación comercial por Vibo), presentaba la mejor evolución. Sus 950 oficinas facturaron 955 M€, un 14,6\% más que en 2010. Sin embargo, en febrero de 2013 estos rsultados no serían suficientes, ya que todas sus oficinas cerraron al público tras el preconcurso de acreedores presentado en los Juzgados.La cuarta plaza era para Carlson Wagonlit Travel, que registraba un volumen de ventas de $500 \mathrm{M} €$, un 2,9\% más que en 2010.

Barceló Viajes ${ }^{7}$ se instalaba en quinto lugar, con un incremento respecto a 2010 de $0,9 \%$.

Almeida Viajes ocupaba la sexta plaza con $324 \mathrm{M} €$, un 6,5\% más que en el ejercicio anterior.

Viajes Jumbo Tours con $254 \mathrm{M} €$ registraba el tercer mayor incremento respecto a 2010, con una variación del $11,1 \%$.

Le seguiría en octavo lugar Viajes Eroski Bidaiak con 218,9 millones, un 5,3\% más que en 2010.

$\mathrm{Al}$ igual que en ediciones anteriores, American Express Barceló mostraba una cierta falta de transparencia, al no facilitar datos sobre su facturación. Si se tiene en cuenta el volumen de ventas obtenido en 2007, último año que presentó sus resultados, se posicionaría en noveno lugar, pero ante la carencia de información, las cifras de esta agencia no se incluían en los resultados globales del ranking.

Nautalia, que inició su andadura en marzo de 2011, tampoco hacía públicos sus datos de facturación.

Tras American Express (Amex) Barceló, en décimo lugar aparecía Olympia Viajes, que experimentaba un descenso de ventas del 2,1\%, hasta alcanzar los 165,9 M€, mientras que IA Viajes cerraba el ranking con 83,7 millones, un $15,6 \%$ más que en 2010 .

\section{Agencias mayoristas}

Las ocho primeras mayoristas de viajes que operaban en el mercado español en 2011, facturaron 2.998 $\mathrm{M} €$. Después de un positivo 2010, donde incrementaron su volumen de negocio un $7 \%$, la incertidumbre económica y la debilidad del consumo interno provocaron un estancamiento de las ventas en 2011. 
Entre las principales novedades del "Ranking NEXOTUR de mayoristas de viajes" (2011) destacaba el cese de operaciones de Nobeltours. Era el segundo año consecutivo en el que caía un gran turoperador, ya que en 2010 había sido Tiempo Libre-Mundicolor.

El ranking en 2011 seguía liderado por la hoy desaparecida, Orizonia, que además ampliaba su distancia con Travelplan. Este grupo cerraba el año con una facturación de $1.093 \mathrm{M} €$, un 7,3\% más que en 2010, cuando se llegaron a alcanzar 1.019 millones.

En segundo lugar aparecía Travelplan con un volumen de ventas de $650 \mathrm{M} €$. Sin embargo, la cifra de negocio registraba el mayor descenso interanual, con una bajada del 11,6\%, $85 \mathrm{M} €$ menos que en 2010.

Pullmantur se afianzaba en la tercera posición. La mayorista propiedad de Royal Caribean cerraba el año con $466 \mathrm{M} €$, un 13,7\% más que en el ejercicio anterior.

Mundosenior mantenía la cuarta plaza, a la que ascendió en 2008. La mayorista había facturado en el último año 318,8 M€, lo que supondría un 10,9\% menos que en 2010.

Soltour, que en 2010 había ascendido a la quinta posición tras la quiebra de Tiempo Libre-Mundicolor, concluía el año con un volumen de ventas de $200 \mathrm{M} €$, un $1 \%$ menos que en 2010 , cuando había facturado $202 \mathrm{M} €$.

Panavisión, aparecía en el sexto lugar con una facturación de 115,2 M€. Cifra que suponía un aumento del 1,4\% respecto a 2010, cuando había superado los $113 \mathrm{M} €$.

Liderando el grupo de turoperadores de grandes viajes, revalidaba su posición Catai Tours, que facturaba $83 \mathrm{M} €$, un $3,3 \%$ más que en 2010 , cuando había rondado los $80 \mathrm{M} €$.

La última posición era para Politours. El ejercicio contable de 2011 concluía con una cifra de negocio de $72 \mathrm{M} €$, lo que había supuesto un decrecimiento del 6,3\% en comparación con los resultados obtenidos en el año anterior.

\section{Agencias online}

Los principales efectos de las Tecnologías de la Información y Comunicación sobre el sector turístico en general y las agencias de viajes en particular, se pueden concretar en la agilización y simplificación del trabajo diario con herramientas integrales y en la multiplicación de canales de promoción y comercialización.

Entre los elementos que han influido en todo ello cabe destacar, por un lado, los cambios acaecidos en el comportamiento del consumidor turístico, puesto que ha pasado de ser un sujeto pasivo para convertirse en un prescriptor; por otro lado, la promoción turística también ha experimentado importantes modificaciones, pasando de una comunicación masiva a una relación one to one.

En el tercer trimestre de 2012, el comercio electrónico en España alcanzaba un volumen de negocio total de facturación de $2.705 \mathrm{M} €$, un $11,7 \%$ más que en el mismo periodo de 2011 . El primer sector era el de las agencias de viajes y operadores turísticos, que copaban el 16,2\% del total, con 438 millones, y que supondría un aumento del 20,3\% respecto al anterior trimestre, según el informe de la Comisión del Mercado de las Telecomunicaciones (CMT, 2012).

Según dicho informe, las reservas de hoteles por Internet, habían supuesto el 1,7\% y el alquiler de coches el 1,5\%. Lo cual indicaba que la mayor parte de las reservas de estos productos, a través de la red, se realizaban por medio de las agencias de viajes online.

Ante este escenario, las agencias virtuales que operan en España han tratado de encontrar su fórmula de negocio y su mercado. A pesar de que en los últimos años han visto como su ritmo de crecimiento mermaba y sus porcentajes de ventas aumentan llegando a ser superiores a los de las grandes agencias tradicionales.

Del "Ranking HOSTELTUR de agencias de viajes online", se puede apreciar como la comparación del total de las ventas de estas agencias aportaba un crecimiento en torno al 16\% en 2011 respecto a 2010. Las cifras correspondían a las ventas realizadas, tanto en el mercado español como en los mercados internacionales.

Los datos de 2011 confirmaban el asentamiento de eDreams como líder indiscutible de las agencias online que operaban en España, con más de $1.100 \mathrm{M}$, una cifra que la situaba a la par de las grandes redes de agencias de viajes presenciales.

El segundo lugar del ranking lo ocupaba Rumbo, que en los últimos años había visto como su volumen de negocio mermaba. Con $495 \mathrm{M} €$ en 2011, crecía un 2\% respecto al año anterior.

En un tercer y cuarto escalón se sitúan Logitravel y Atrápalo con cifras de facturación superiores a los $200 \mathrm{M} €$. Cabe destacar el caso de Logitravel que había crecido mucho en los últimos tres años. En 2011 aumentó sus ventas un 40\%, mientras que Atrápalo lo había hecho en un 30\%. 
Una estrategia online en el sector viajes que en época de crisis parecía que iba a funcionar, fue la fórmula outlet o cupón descuento y, sin embargo, no ha llegado a calar en el mercado, siendo un ejemplo de ello la francesa Voyages Privé. Pero lo que sí ha resultado significativo es la incursión en los viajes de los grandes portales oulet como Groupon, Lest Bonus, Planeo o Groupalia, entre otros.

Una vez analizada la situación de las principales agencias de viajes que operan en el mercado español, cabe reseñar que el progresivo aumento del hábito del mercado emisor en reservar viajes a través de Internet se está dejando sentir entre las agencias tradicionales, que ven como cada vez entran menos clientes potenciales en sus oficinas.

La competencia ocasionada por las agencias online, que siguen creciendo en plena crisis, así como la apuesta por la venta directa de los proveedores, especialmente los transportistas, son también los causantes de los problemas por los que atraviesan las agencias tradicionales.

Para sobrevivir, las pequeñas agencias tienden a apostar, además de por el aprovechamiento de las tecnologías, por la especialización y la puesta en valor de los factores que las diferencian de la oferta online. Es decir, trato personalizado y asesoramiento.

\section{El marketing de afiliación y su potencialidad en la intermediación turística}

Si se parte de la premisa de que la publicidad es una técnica que adquiere cada vez más importancia en el proceso de organización de las agencias (Albert, 1999), puede entenderse que el marketing de afiliación se esté consolidando como una herramienta clave en la implementación de la publicidad del sector turístico en general y de las agencias de viaje en particular, al generar una oportunidad de negocio sin necesidad de realizar grandes inversiones en logística y sin obligaciones financieras o de gestión administrativa.

Este tipo de comunicación comercial, también denominado de resultados, es una especialidad del marketing interactivo caracterizado por la consecución de resultados concretos y medibles de las campañas publicitarias. Engloba todas aquellas relaciones comerciales en las que un anunciante promociona sus servicios o productos mediante anuncios en las páginas de sus afiliados o publisher (IAB, 2010).

\section{Cuadro 1: EL Marketing de Afiliación.}

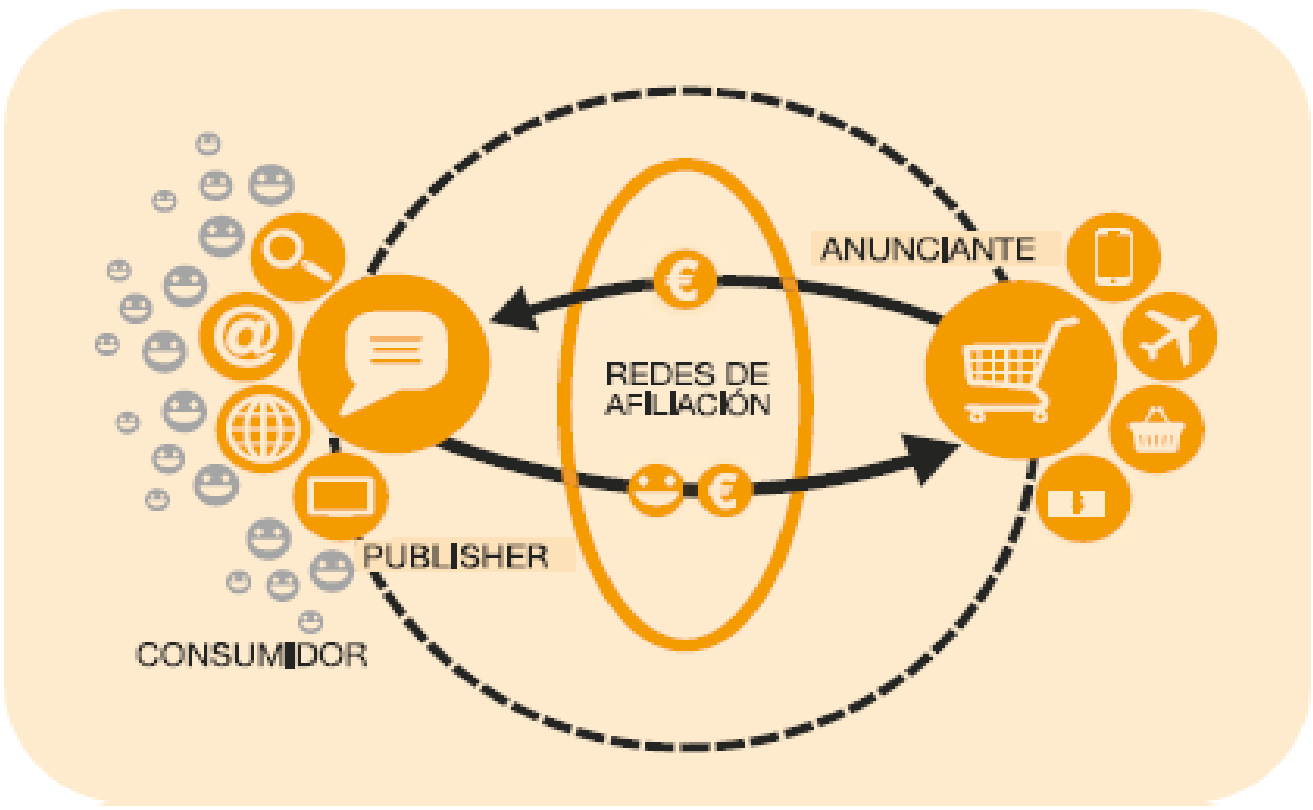

Fuente: IAB, (2010) 
Goldschmidt (2003) considera las razones por las que las empresas deberían desarrollar esta estrategia de marketing: obtener el valor de estar conectado a muchos otros recursos; beneficiarse de los efectos de red; y, en última instancia, crear un mayor valor para sí mismos.

Brown (2009) trata la afiliación desde parámetros de rentabilidad, al afirmar que es un método de publicidad en línea altamente eficaz, en el que los comerciantes pagan a un sitio Web independiente para promover los productos o servicios de un anunciante.

La IAB (2010) clasifica la afiliación en función de los tipos de afiliados; así establece seis categorías de afiliados: páginas Web con contenidos específicos y de interés personal; cash back y sitios que reparten sus ingresos con los usuarios finales; PPC afiliados que trabajan en motores de búsqueda ó buscadores; bases de datos de e-mail marketing; bases de datos de co-registro y redes de afiliación.

En cuanto a los modelos de negocio donde se desarrolla afiliación y centrándonos en el European Affiliate Marketing Landscape Report (2011), puede puntualizarse que el más extendido es el desarrollado en portales, tanto verticales como horizontales, con un $21 \%$ del total de la inversión; le siguen los datafeed y los comparadores con un $12 \%$ ambos, para después encontrarse con los nichos, $11,53 \%$, el modelo cash back con un 10,56\% y el e-mail con un 7,15\%. El resto de opciones muestran porcentajes más bajos, desde $7 \%$ del SEM hasta el 1\% de las redes sociales o los co-registros. Es significativo que siendo las redes sociales un fenómeno en clara expansión, en lo que se refiere a los modelos de negocio en los cuales se desarrolla el marketing de afiliación todavía no se puede decir que tengan excesiva repercusión.

\section{Cuadro 2: Modelos de Negocio}

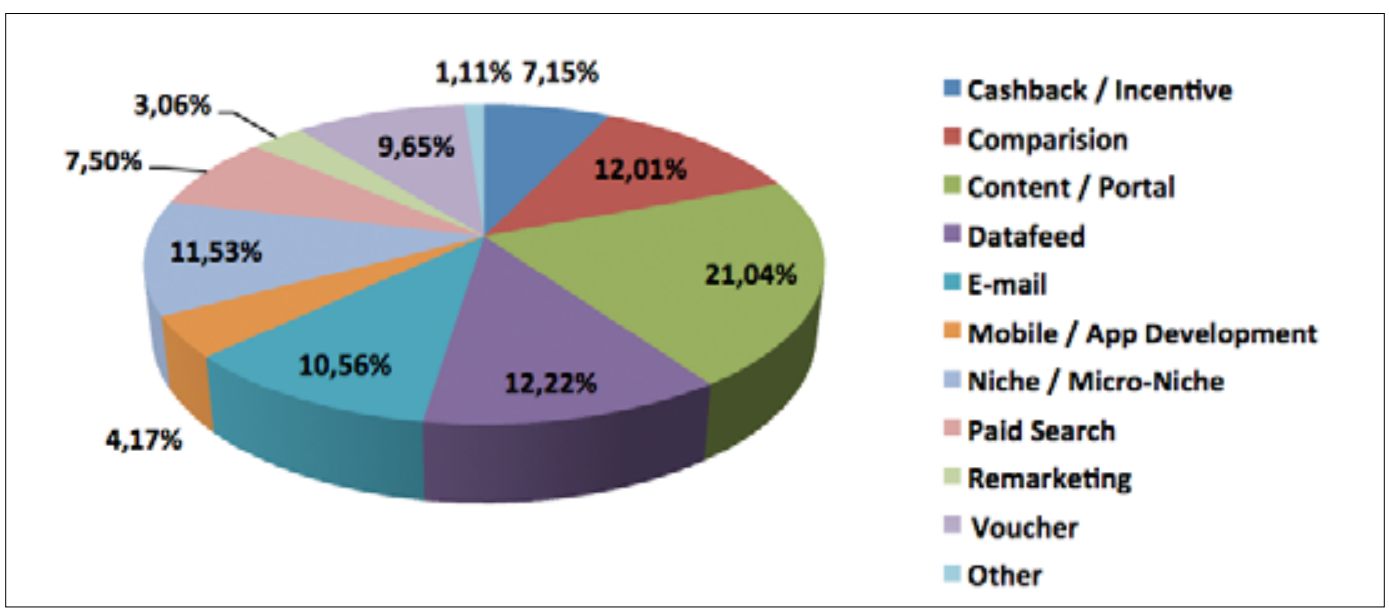

Fuente: Adaptado de European Affiliate Marketing Landscape Report (2011)

Respecto a las herramientas útiles para el desarrollo del marketing de afiliación en los modelos de negocios, el mismo informe señala como métodos más utilizados: enlaces de texto; banners; data feeds; catálogos de códigos libres; plugins wordpress y vídeos.

Por regla general, un afiliado entra de forma habitual en uno o varios programas de afiliación ${ }^{8}$ que le generan un beneficio a modo de porcentaje sobre las ventas realizadas en la web del anunciante. Las remuneraciones por afiliación pueden plasmarse de diferentes maneras, por ejemplo el clic, el doble clic, los formularios, las ventas etc., y varían en función del sector de actividad y de los productos de la empresa anunciante.

En el año 2001 existían más de un millar de programas (Silverstein, 2001), de los que Amazon. com era el más importante (Bruner, Harden y Heyman, 2001). Y aunque se trata de una disciplina relativamente novedosa, el marketing de afiliación ya ha experimentado importantes cambios a lo largo de los últimos años (1994-2012). Así puede hablarse de Afiliación 1.0: del Banner al CPA; de Afiliación 2.0: Display y SEM; y, por último de Afiliación 3.0: la nueva generación.

Después de ocho años de desarrollo del marketing de afiliación en España, con más de una veintena de plataformas en el mercado (aunque el $80 \%$ del negocio lo gestionen diez), el modelo de pago por 
resultados se enfrentó a nuevos retos y desafíos en el año 2012. En opinión de Valdivielso (2011), el marketing de afiliación en España se enfrenta a: competencia feroz; long-tail en entredicho; escaso grado de fidelización y desconocimiento del modelo de afiliación; formatos creativos en tela de juicio; falta de campañas de tráfico cualificado; reducido número de anunciantes; $\mathrm{y}$, un análisis de resultados pobre.

Las webs afiliadas actúan como herramienta del anunciante a la hora de dar a conocer sus productos y generarles ventas, de las cuales se obtiene la comisión correspondiente para dicho portal(es) afiliado(s). Es una relación muy estrecha que permite crear vínculos profesionales entre anunciantes y afiliados, basados en una relación de idoneidad, así como afianzados gracias a la reputación del afiliado y a la relevancia de la calidad del contenido del site del afiliado e igualmente del posicionamiento ostentado por el producto del anunciante; además, gracias a la viralidad del canal, junto a la reputación, la relevancia y la confianza, la facilidad para alcanzar el objetivo de la afiliación se antoja más factible.

A todo ello cabe añadir que se generan más opciones para establecer alianzas y sinergias, lo cual permite aumentar los tiempos de conectividad e incrementar las opciones de éxito. Por último, la intensidad de los incentivos, es decir mayores y mejores remuneraciones, hace que las cadenas formadas en afiliación ayuden al éxito.

Entre las ventajas generales que pueden ofrecer los programas de afiliación para el subsector de las agencias de viajes están: permitir tener una red online de prescriptores que cobran por resultados generados; ofrecer capacidad de segmentación para llegar al target adecuado; mayor capacidad de integración con los medios afines al producto o servicio; posibilitar la optimización para conseguir los mejores resultados; controlar el gasto publicitario en tiempo real; alta capacidad de medición y métricas y menor gasto en inversión publicitaria que con otras estrategias de marketing (IAB, 2010).

\section{Objetivo, hipótesis y metodología de la investigación}

El objetivo de este artículo se fundamenta en analizar la relación existente entre la intermediación turística en España (agencias de viajes offline o tradicionales y online) y el marketing de afiliación.

Dicho objetivo surge como consecuencia de la importancia que, cada vez más, alcanza esta herramienta en el sector travel; así como de la revisión de la literatura científica que trata sobre esta disciplina y que muestra actualmente un limitado número de trabajos. E igualmente, por la importancia que puede llegar a alcanzar la utilización de esta herramienta en el ámbito online, por parte de las agencias.

A continuación se detallan las hipótesis de trabajo que subyacen al objetivo de estudio y que surgen como consecuencia del análisis efectuado en el marco teórico:

Hipótesis I: Las empresas de intermediación turística españolas se decantan por implementar el marketing de afiliación de manera paulatina.

Hipótesis II: La importancia y repercusión del marketing de afiliación para las empresas de intermediación turística españolas offline es similar a las online.

Hipótesis III: Las empresas de intermediación turística españolas están destinadas a utilizar herramientas online, como el marketing de afiliación, para comercializar sus productos.

La metodología de la investigación se asienta por un lado, en la utilización de fuentes secundarias, las cuales se han apoyado principalmente en la información facilitada por empresas privadas que desarrollan el marketing de afiliación: IAB; publicaciones relacionadas con agencias de viajes: HOSTELTUR o NEXOTUR, así como por fuentes documentales publicadas por determinados organismos públicos y privados relacionados con el turismo: IET, FRONTUR, FAMILITUR...

Por otro lado, la utilización de fuentes primarias mediante la realización de entrevistas en profundidad ha supuesto un método de obtención de información muy conveniente para poder extraer, entre otras cosas, información compleja, confidencial o juicios abiertos ante la información requerida (Taylor y Bogard, 1992; Delgado y Gutiérrez, 1994; Sarabia, 1999 y Grande y Abascal, 2000).

En este trabajo, la aplicación de una investigación cualitativa se sustenta en la existencia de diversos estudios relacionados con el ámbito de las agencias de viajes, en las que la utilización de entrevistas en profundidad han jugado un papel relevante para: analizar el objeto de estudio; como primera aproximación a una posterior investigación cuantitativa o como complemento al uso de otras técnicas de tipo cualitativo. Cabe destacar así en relación a la revisión de la literatura, los trabajos realizados por Parra, Melchor y Ramos (2003); Rodríguez del Bosque, San Martín y Collado (2005); Moreno y Aguiar (2006); Andreu, Currás y Sánchez (2009); Galhanone, Marques, Toledo y Mazzon (2010); Guijarro (2010); Berné, García y García (2011, 2012). 
Dada la naturaleza de esta investigación y el objetivo de la misma, en el que se trataba de abordar un problema concreto con una muestra relativamente limitada de expertos y profesionales del sector, se optó por entrevistas de carácter semiestructurado, en las que a partir de un guión inicial con los aspectos a abordar, se adaptó su desarrollo en función del entrevistado y la evolución de las mismas (Trespalacios, Vázquez y Bello, 2005; Grande y Abascal, 2011).

En relación a la búsqueda de resultados concluyentes sobre el fenómeno a investigar, se elaboró un guión con preguntas meditadas y estructuradas, si bien se dotó a la entrevista de una cierta flexibilidad y por ello un planteamiento de tipo semiestructurado en aras a recoger posibles respuestas por parte de los expertos que no hubiese sido contemplada previamente y que pudiese aportar información relevante a la investigación (Trespalacios, Vázquez y Bello, 2005; Grande y Abascal, 2011).

Así, la fase cualitativa incluyó un total de treinta entrevistas personales, realizadas durante el periodo 2009-2011.

En las mismas se planteaban doce cuestiones, con secuencia de embudo (Esomar, 1973). Para contactar con dichas personas nos dirigimos personalmente a ellas, de manera telefónica ó a través del correo electrónico, exponiéndoles el objetivo de la investigación y solicitando su colaboración. Con aquellas que accedieron a la petición, posteriormente se desarrollaron las entrevistas de manera directa y personal.

En los siguientes cuadros, se muestran los participantes en este estudio, el cargo que ocupan en la actualidad ó habían ocupado en el momento de las entrevistas y la empresa en la que desarrollaban su actividad.

Cuadro 3: Entrevistados investigación cualitativa: Plataformas de Afiliación

\begin{tabular}{|c|c|c|}
\hline ENTREVISTADO & CARGO & EMPRESA \\
\hline $\boldsymbol{E} 1$ & Team Leader Spain & Zanox \\
\hline $\boldsymbol{E} \boldsymbol{2}$ & Executive Sales Directivo & Zanox \\
\hline $\boldsymbol{E} 3$ & Head of Consultancy & Tradedoubler \\
\hline $\boldsymbol{E} 4$ & Product Manager & Netfilia \\
\hline $\boldsymbol{E} 5$ & Operational Director & Affilinet \\
\hline $\boldsymbol{E} \boldsymbol{E}$ & Head of Network & Affiliatefuture \\
\hline $\boldsymbol{E} 7$ & Country Manager Spain-Portugal & Publicidées \\
\hline $\boldsymbol{E} 8$ & Account Manager & Webgains \\
\hline
\end{tabular}

Fuente: Elaboración propia

\section{Cuadro 4: Entrevistados investigación cualitativa: Panel de Expertos}

\begin{tabular}{|c|c|c|}
\hline ENTREVISTADO & CARGO & EMPRESA \\
\hline $\boldsymbol{E 9}$ & CEO España \& LATAM & Adsmarket \\
\hline $\boldsymbol{E 1 0}$ & Regional Manager ES, PT \& LATAM & Zanox \\
\hline $\boldsymbol{E 1 1}$ & CEO & GEA Internet Project Consulting \\
\hline $\boldsymbol{E 1 2}$ & Directivo marketing & IE Business School \\
\hline $\boldsymbol{E 1 3}$ & $\begin{array}{c}\text { Ph.D. en Management. especialidad } \\
\text { en Information Systems } \\
\text { UCLA, California }\end{array}$ & Inka Marketing Estratégico \\
\hline $\boldsymbol{E 1 4}$ & Directivo comercial & Impacting \\
\hline $\boldsymbol{E 1 5}$ & Business Development Director & \\
\hline
\end{tabular}

Fuente: Elaboración propia 
Cuadro 5: Entrevistados investigación cualitativa: Agencias Mayoristas

\begin{tabular}{|c|c|c|}
\hline ENTREVISTADO & CARGO & EMPRESA \\
\hline$E 16$ & $\begin{array}{l}\text { Responsable Redes } \\
\text { Sociales,Departamento de } \\
\text { Marketing Online }\end{array}$ & Politours \\
\hline$E 17$ & Product Manager & Panavisión \\
\hline$E 18$ & Product Manager & Panavisión \\
\hline E19 & External MK Advisor & Barcelóviajes.com \\
\hline$E 20$ & Directivo & $\begin{array}{c}\text { Viajes Andrómeda. Business Plus } \\
\text { Lufthansa City Center }\end{array}$ \\
\hline
\end{tabular}

Fuente: Elaboración propia

Cuadro 6: Entrevistados investigación cualitativa: Agencias Minoristas

\begin{tabular}{|c|c|c|}
\hline ENTREVISTADO & CARGO & EMPRESA \\
\hline $\boldsymbol{E 2 1}$ & Directivo & Viajes David Caamaño \\
\hline $\boldsymbol{E 2 2}$ & Directivo & Viaxes Narón \\
\hline $\boldsymbol{E 2 3}$ & Directivo & $\begin{array}{c}\text { CXG.Viaxes Corporación Caixa } \\
\text { Galicia }\end{array}$ \\
\hline $\boldsymbol{E 2 4}$ & Directivo & Viajes Cuzco \\
\hline $\boldsymbol{E 2 5}$ & Directivo & Nuba \\
\hline
\end{tabular}

Fuente: Elaboración propia

Cuadro 7: Entrevistados investigación cualitativa. Agencias online

\begin{tabular}{|c|c|c|}
\hline ENTREVISTADO & CARGO & EMPRESA \\
\hline $\boldsymbol{E 2 6}$ & Senior Account Manager & Tripadvisor \\
\hline $\boldsymbol{E 2 7}$ & Sales Manager & Travelzoo \\
\hline $\boldsymbol{E 2 8}$ & Ceo Manager & Minube \\
\hline $\boldsymbol{E 2 9}$ & Responsable de Afiliación & Destinia \\
\hline $\boldsymbol{E 3 0}$ & Customer Marketing Manager & Lastminute \\
\hline
\end{tabular}

Fuente: Elaboración propia

\section{Análisis de los resultados}

Para una mejor aproximación a la realidad de la afiliación y a su vinculación con la intermediación turística en España, a continuación se procede a contrastar las hipótesis de estudio, de modo que se presentan los resultados obtenidos en las entrevistas, lo que permitirá confirmar ó refutar las conjeturas planteadas.

Hipótesis I: Las empresas de intermediación turística españolas se decantan por implementar el marketing de afiliación de manera paulatina.

En los siguientes cuadros se muestran las opiniones de ocho responsables de las principales plataformas de afiliación; siete expertos en marketing; cinco responsables de marketing y producto de agencias mayoristas tradicionales; cinco responsables de agencias minoristas tradicionales y cinco responsables de producto, cuentas y afiliación de agencias online. Para facilitar la comprensión, los resultados se presentan manteniendo dicho orden. 


\section{Cuadro 8: Resultados entrevistas}

\begin{tabular}{|c|c|}
\hline $\begin{array}{l}\text { Entrevistados: } \\
\text { Plataformas de } \\
\quad \text { Afiliación }\end{array}$ & $\begin{array}{c}\text { Implementación del marketing de afiliación en la intermediación } \\
\text { turistica en España. }\end{array}$ \\
\hline$E 1$ & $\begin{array}{c}\text { "La implementación de esta herramienta es un proceso a largo plazo. La idea } \\
\text { es establecer un programa de afiliación con buenas bases para conseguir los } \\
\text { objetivos" }\end{array}$ \\
\hline$E 2$ & $\begin{array}{c}\text { "El marketing de afiliación no se trabaja a c/p, requiere un crecimiento y un } \\
\text { período de adaptación para agencias y afiliados" }\end{array}$ \\
\hline E3 & $\begin{array}{l}\text { "Aunque el modelo de desarrollo de marketing de afiliación sea el mismo, las } \\
\text { agencias online llevan más tiempo utilizando esta herramienta que las offline" }\end{array}$ \\
\hline$E 4$ & $\begin{array}{c}\text { "Las agencias offline, a excepción de Viajes Iberia y Barceló, todavía no han } \\
\text { entrado en afiliación, porque en muchos casos no tienen una buena plataforma } \\
\text { online" }\end{array}$ \\
\hline E5 & $\begin{array}{l}\text { "En las agencias tradicionales la implementación va más lenta, debido en gran } \\
\text { parte a que tienen un canal de distribución offline muy potente" }\end{array}$ \\
\hline$E 6$ & $\begin{array}{l}\text { "Existen bastantes agencias que ya utilizan el marketing de afiliación y lo } \\
\text { recomiendan a sus clientes como una manera de conseguir tráfico online y ventas" }\end{array}$ \\
\hline$E 7$ & $\begin{array}{c}\text { "Está más desarrollado en las online que en las offline, no siendo conscientes estas } \\
\text { últimas del riesgo que corren, como les ocurrió en EEUU" }\end{array}$ \\
\hline$E 8$ & "Sobre todo en las online" \\
\hline
\end{tabular}

Fuente: Elaboración propia

\section{Cuadro 9: Resultados entrevistas}

\begin{tabular}{|c|c|}
\hline $\begin{array}{l}\text { Entrevistados: } \\
\text { Panel de expertos }\end{array}$ & $\begin{array}{c}\text { Implementación del marketing de afiliación en la intermediación } \\
\text { turística en España. }\end{array}$ \\
\hline E9 & $\begin{array}{c}\text { "Se han adaptado perfectamente; en España ha empezado por los servicios online } \\
\text { de las OTA,s" }\end{array}$ \\
\hline$E 10$ & $\begin{array}{c}\text { "En España la afiliación empezó con las aerolíneas, aunque pronto las agencias, } \\
\text { tanto las pureplayers como las offline lo utilizaron, usándola éstas últimas como } \\
\text { complemento a su canal de ventas" }\end{array}$ \\
\hline$E 11$ & "La implementación es baja, aunque las online sí lo están utilizando" \\
\hline$E 12$ & $\begin{array}{c}\text { "El marketing de afiliación en general puede suponer una amenaza, no } \\
\text { obstante puede generar una oportunidad para aquellas agencias que no están } \\
\text { especializadas" }\end{array}$ \\
\hline$E 13$ & "Es como en cualquier otro sector que irrumpe en Internet" \\
\hline$E 14$ & $\begin{array}{c}\text { "Las agencias lo ven como una amenaza, igual que ven todo el mundo online. } \\
\text { Pueden ser canales complementarios o competencia directa depende cómo lo } \\
\text { quiera utilizar cada turoperador" }\end{array}$ \\
\hline$E 15$ & $\begin{array}{c}\text { "Para las agencias es necesario tener presencia en Internet y el marketing de } \\
\text { afiliación es una herramienta muy interesante para ello. Se paga por resultado, } \\
\text { así que las agencias pueden determinar cuál es el coste adecuado por venta de } \\
\text { vuelo, hotel, ..." }\end{array}$ \\
\hline
\end{tabular}

Fuente: Elaboración propia 


\section{Cuadro 10: Resultados entrevistas}

\begin{tabular}{|c|c|}
\hline $\begin{array}{c}\text { Entrevistados: } \\
\text { Agencias } \\
\text { Mayoristas }\end{array}$ & $\begin{array}{c}\text { Implementación del marketing de afiliación en la intermediación } \\
\text { turistica en España. }\end{array}$ \\
\hline $\boldsymbol{E 1 6}$ & "Nosotros como agencia mayorista independiente somos diferentes" \\
\hline $\boldsymbol{E 1 7}$ & $\begin{array}{c}\text { "Existen muchas agencias que quieren un contacto directo con las personas, por } \\
\text { eso llaman aunque tengan información en la web" }\end{array}$ \\
\hline $\boldsymbol{E 1 8}$ & "Yo lo veo muy útil, porque facilita información" \\
\hline $\boldsymbol{E 1 9}$ & $\begin{array}{c}\text { "El sector de viajes es especial, ya que existe un pequeño grupo de afiliados que } \\
\text { dominan el mercado llegando a realizar complejas integraciones del producto } \\
\text { de las agencias para llegar a convertirse en metabuscadores o especialistas en } \\
\text { marketing en buscadores" }\end{array}$ \\
\hline $\mathbf{E 2 0}$ & $\begin{array}{c}\text { "Pendiente de conocerla mejor, es una metodología desconocida, sobre todo para la } \\
\text { mediana y pequeña agencia." }\end{array}$ \\
\hline
\end{tabular}

Fuente: Elaboración propia

\section{Cuadro 11: Resultados entrevistas}

\begin{tabular}{|c|c|}
\hline $\begin{array}{c}\text { Entrevistados: } \\
\text { Agencias } \\
\text { Minoristas }\end{array}$ & $\begin{array}{c}\text { Implementación del marketing de afiliación en la intermediación } \\
\text { turística en España. }\end{array}$ \\
\hline$E 21$ & $\begin{array}{c}\text { "Habrá productos que se adapten a esta forma de venta y publicidad, pero otros } \\
\text { que requerirán más asesoramiento" }\end{array}$ \\
\hline E22 & $\begin{array}{l}\text { "Tal y como está el mercado minorista se puede considerar una oportunidad el } \\
\text { poder utilizar esta herramienta para comercializar los productos en la Red". }\end{array}$ \\
\hline E23 & $\begin{array}{l}\text { "Salvo las grandes compañías online, en el resto la implantación es baja, creo que } \\
\text { por desconocimiento". }\end{array}$ \\
\hline$E 24$ & "Veo que no se conoce, al menos en mi sector" \\
\hline E25 & "Lo veo interesante, aunque lento y poco fiable". \\
\hline
\end{tabular}

Fuente: Elaboración propia

\section{Cuadro 12: Resultados entrevistas}

\begin{tabular}{|c|c|}
\hline $\begin{array}{l}\text { Entrevistados: } \\
\text { Agencias online }\end{array}$ & $\begin{array}{c}\text { Implementación del marketing de afiliación en la intermediación } \\
\text { turística en España. }\end{array}$ \\
\hline E26 & "Es uno de los sectores donde más se está aplicando y con mejores resultados" \\
\hline$E 27$ & $\begin{array}{c}\text { "Hay divisiones pero las tradicionales lo están utilizando cada vez más como canal } \\
\text { de venta" }\end{array}$ \\
\hline E28 & "Cada vez se está utilizando con mejores resultados" \\
\hline E29 & $\begin{array}{c}\text { "Es esencial, la afiliación representa un porcentaje nada despreciable de las ventas } \\
\text { del sector. Aun así el fin de esta acción siempre está dirigido a la fidelización del } \\
\text { cliente, objetivo que se alcanza con bastante esfuerzo" }\end{array}$ \\
\hline E30 & $\begin{array}{c}\text { "Es como algo esencial que permite expandir la actividad de venta de cualquier } \\
\text { agencia a soportes ajenos al suyo, alcanzando un público objetivo mucho mayor } \\
\text { con una fracción del coste que supondría conseguir los mismos visitantes/ventas a } \\
\text { través de una estrategia orgánica." }\end{array}$ \\
\hline
\end{tabular}

Fuente: Elaboración propia 
Los resultados procedentes de las entrevistas en profundidad a expertos en la materia, sintetizados en los anteriores cuadros, evidencian que la aplicación del marketing de afiliación por parte de las agencias de viajes españolas requiere de un proceso de adaptación largo y complejo, si bien existe un cierto consenso a la hora de valorar que se trata de un modelo interesante susceptible de ofrecer importantes oportunidades a las empresas.

Sin embargo, hay quienes apuntan que el desconocimiento de esta herramienta, contribuye también a generar cierta desconfianza en relación a los beneficios que les pueda reportar tanto a medio como a largo plazo. De modo que ese desconocimiento provoca incertidumbre, ello da lugar a un cierto freno a la hora de decidir sobre la utilización de dicha herramienta.

Los expertos que conforman la muestra elegida para realizar la investigación objeto de este artículo ponen de manifiesto la existencia de una clara ventaja para las agencias online, al percibir que la implementación es más fácil, esencial e importante, por lo que son cada vez más las que abogan por utilizar este tipo de marketing para publicitar sus productos y servicios. Mientras las agencias tradicionales siguen basando principalmente sus estrategias en el canal offline, sobre todo por el desconocimiento y por ende la desconfianza que les transmite esta herramienta, sin obviar que en un futuro su comercialización pasará inevitablemente por considerar el marketing de afiliación como una herramienta esencial en su modelo de negocio.

Las empresas de intermediación turística en España son, por tanto, conscientes de la importancia que representa esta estrategia, por la cual manifiestan la necesidad de implementarla, pero de forma progresiva.

Consiguientemente se puede confirmar la Hipótesis I y por ello se acepta.

Hipótesis II: La importancia y repercusión del marketing de afiliación para las empresas de intermediación turística españolas offline es similar a las online.

\section{Cuadro 13: Resultados entrevistas}

\begin{tabular}{|c|c|}
\hline $\begin{array}{l}\text { Entrevistado: } \\
\text { Plataformas de } \\
\quad \text { afiliación }\end{array}$ & $\begin{array}{l}\text { Misma importancia y repercusión del marketing de afiliación en las } \\
\text { empresas de intermediación turística españolas offline y online. }\end{array}$ \\
\hline$E 1$ & $\begin{array}{l}\text { "Depende más de si las offline tienen su réplica online. Por tecnología y objetivos } \\
\text { se adapta más a las online" }\end{array}$ \\
\hline$E 2$ & $\begin{array}{l}\text { "A las agencias offline les falta CRM y tecnología. Las agencias online en cambio } \\
\text { lo utilizan mucho" }\end{array}$ \\
\hline E3 & $\begin{array}{c}\text { "Obviamente en España no, aunque el modelo de desarrollo sea el mismo. Las } \\
\text { pocas offline que han llegado al mercado online lo han hecho más tarde, aunque } \\
\text { con fuerza" }\end{array}$ \\
\hline$E 4$ & $\begin{array}{l}\text { "Las offline que tienen presencia online utilizan los programas de la misma } \\
\text { manera que las online, lo que cambian es el modelo de negocio" }\end{array}$ \\
\hline E5 & $\begin{array}{l}\text { "Las offline, debido a sus distribuidores, entre otros aspectos, les cuesta mucho } \\
\text { introducirse en el online. Además hay un desconocimiento de lo que esta } \\
\text { herramienta les puede ofrecer, por lo que son pocas las que lo utilizan" }\end{array}$ \\
\hline E6 & $\begin{array}{l}\text { "Es muy diferente. El tipo de producto que venden las offline como los } \\
\text { Viajes Combinados, que en pocas redes de afiliación se ofrecen, junto con } \\
\text { el desconocimiento y la falta de tecnología hace que éstas no utilicen esta } \\
\text { herramienta en la misma medida que las online" }\end{array}$ \\
\hline$E 7$ & "No, las offline están utilizando esta herramienta en menor medida" \\
\hline E8 & "No, las offline todavía no lo tienen implantado" \\
\hline
\end{tabular}

Fuente: Elaboración propia 


\section{Cuadro 14: Resultados entrevistas}

\begin{tabular}{|c|c|}
\hline $\begin{array}{c}\text { Entrevistado: Panel } \\
\text { de expertos }\end{array}$ & $\begin{array}{c}\text { Misma importancia y repercusión del marketing de afiliación en las } \\
\text { empresas de intermediación turistica españolas offline y online. }\end{array}$ \\
\hline $\boldsymbol{E 9}$ & $\begin{array}{c}\text { "No. Aunque los grandes grupos como Ecuador lo están haciendo muy bien, los } \\
\text { pequeños grupos no" }\end{array}$ \\
\hline $\boldsymbol{E} 10$ & $\begin{array}{c}\text { "Las pureplayers tienen más adecuación al medio, por su adaptación tecnológica } \\
\text { para establecer vínculos con las plataformas que una offline" }\end{array}$ \\
\hline $\boldsymbol{E 1 1}$ & $\begin{array}{c}\text { "Sí. Creo que si no fuera porque la legislación lo impide, pasaría como en EEUU, } \\
\text { todo el mundo vendería viajes desde su casa como afiliados de una agencia" }\end{array}$ \\
\hline $\boldsymbol{E 1 2}$ & "Por supuesto en las agencias online más que en las offline" \\
\hline $\boldsymbol{E 1 3}$ & $\begin{array}{c}\text { "La realidad es que las offline no están haciendo mucha afiliación, algo más las } \\
\text { online" }\end{array}$ \\
\hline $\boldsymbol{E 1 4}$ & "No. Es una ayuda para la agencia especializada y para el turoperador" \\
\hline $\boldsymbol{E 1 5}$ & $\begin{array}{c}\text { "Las agencias online lo han tenido más fácil porque su modelo de negocio desde } \\
\text { el primer momento ha estado orientado al comercio online, pero incluso las } \\
\text { agencias tradicionales tienen que actualizarse para competir con las online" }\end{array}$ \\
\hline
\end{tabular}

Fuente: Elaboración propia

\section{Cuadro 15: Resultados entrevistas}

\begin{tabular}{|c|c|}
\hline $\begin{array}{c}\text { Entrevistados: } \\
\text { Agencias mayoristas }\end{array}$ & $\begin{array}{l}\text { Misma importancia y repercusión del marketing de afiliación en las } \\
\text { empresas de intermediación turistica españolas offline y online. }\end{array}$ \\
\hline E16 & $\begin{array}{c}\text { "No. En una offline se le da mucha más información al cliente, por lo que el } \\
\text { modelo de marketing de afiliación ha de ser diferente" }\end{array}$ \\
\hline$E 17$ & "Por supuesto que más en las online" \\
\hline E18 & "Más en las online" \\
\hline E19 & $\begin{array}{c}\text { "No creo que podamos establecer una diferenciación entre el tipo de integración, } \\
\text { pero sí que las opciones y creatividades varían en función del nivel de desarrollo } \\
\text { que cada agencia tiene en sus XML, o en su capacidad de segmentación de su } \\
\text { catálogo de productos" }\end{array}$ \\
\hline$E 20$ & $\begin{array}{c}\text { "No, sin embargo no debería ser así, pues es una herramienta útil para ambos } \\
\text { mercados" }\end{array}$ \\
\hline
\end{tabular}

Fuente: Elaboración propia

\section{Cuadro 16: Resultados entrevistas}

\begin{tabular}{|c|c|}
\hline $\begin{array}{c}\text { Entrevistado: } \\
\text { Agencias minoristas }\end{array}$ & $\begin{array}{c}\text { Misma importancia y repercusión del marketing de afiliación en las } \\
\text { empresas de intermediación turistica españolas offline y online. }\end{array}$ \\
\hline E21 & "Sí, claro que sí" \\
\hline $\boldsymbol{E 2 2}$ & $\begin{array}{c}\text { "Sí. Nosotros en las agencias minoristas no utilizamos esta herramienta } \\
\text { prácticamente; mientras que estoy segura que las online sí." }\end{array}$ \\
\hline $\boldsymbol{E 2 3}$ & $\begin{array}{c}\text { "Si las offline terminan abocando al cliente a la visita personalizada a su } \\
\text { establecimiento, la oportunidad y las ventajas de esta herramienta se pierden } \\
\text { de esta manera". }\end{array}$ \\
\hline $\boldsymbol{E 2 4}$ & "No, supongo que las online lo utilizan más que nosotros" \\
\hline $\boldsymbol{E 2 5}$ & "No, creo que en general las empresas siguen sin hacer afiliación." \\
\hline
\end{tabular}

Fuente: Elaboración propia 


\section{Cuadro 17: Resultados entrevistas}

\begin{tabular}{|c|c|}
\hline $\begin{array}{l}\text { Entrevistados: } \\
\text { Agencias online }\end{array}$ & $\begin{array}{l}\text { Misma importancia y repercusión del marketing de afiliación en las } \\
\text { empresas de intermediación turística españolas offline y online. }\end{array}$ \\
\hline$E 26$ & $\begin{array}{c}\text { "En las offline prácticamente no se está haciendo, ya que esta herramienta } \\
\text { necesita una conversión para funcionar de búsquedas a ventas" }\end{array}$ \\
\hline$E 27$ & $\begin{array}{c}\text { "Está teniendo más repercusión en las online en obtener más beneficio, ya que } \\
\text { éstas lo conocen y lo aplican en mayor medida" }\end{array}$ \\
\hline E28 & $\begin{array}{l}\text { "Pues no lo sé. Desconozco cómo funciona el sector de viajes tradicional en este } \\
\text { punto" }\end{array}$ \\
\hline E29 & "Desconozco como se utiliza la afiliación en el mercado offline." \\
\hline E30 & $\begin{array}{c}\text { "Por supuesto: el marketing de afiliación es una actividad 100\% online. Si la } \\
\text { agencia en cuestión no tiene una estrategia online, la afiliación será residual o } \\
\text { inexistente y muy probablemente no supondrá ningún beneficio adicional a su } \\
\text { negocio" }\end{array}$ \\
\hline
\end{tabular}

Fuente: Elaboración propia

Según los resultados obtenidos en las entrevistas, aunque el modelo de desarrollo del marketing de afiliación en las agencias online y en las offline es el mismo, la importancia, repercusión y el uso de esta herramienta varía en función de sus tipologías.

Las agencias online, conforme a lo ya comentado, se adecúan mejor al medio. Mientras que las tradicionales u offline, salvo excepciones como Viajes El Corte Inglés ${ }^{9}$ o Barceló Viajes ${ }^{10}$, están infrautilizando el canal online, de ahí que les cueste más introducir esta herramienta en su estrategia de comercialización por el tipo de producto que ofrecen y la importancia dada a la relación personal con el cliente.

Se puede así constatar que para las empresas de intermediación turística españolas, la implementación del marketing de afiliación como herramienta online, no tiene la misma importancia ni repercusión en el caso de las agencias offline que en las online. Se refuta por tanto, en este caso, la Hipótesis II.

Hipótesis III: Las empresas de intermediación turística españolas están destinadas a utilizar herramientas online, como el marketing de afiliación, para comercializar sus productos.

\section{Cuadro 18: Resultados entrevistas}

\begin{tabular}{|c|c|}
\hline $\begin{array}{l}\text { Entrevistados: } \\
\text { Plataformas de } \\
\text { afiliación }\end{array}$ & $\begin{array}{c}\text { Relación futura entre el marketing de afiliación y las empresas de } \\
\text { intermediación turística españolas. }\end{array}$ \\
\hline$E 1$ & "Están abocadas a entenderse" \\
\hline E2 & $\begin{array}{l}\text { "Una evolución pareja para adaptarse a la evolución de la red; cada vez la gente } \\
\text { viaja más y lo hace también más a través de internet" }\end{array}$ \\
\hline E3 & $\begin{array}{l}\text { "El modelo que utiliza el marketing de afiliación tiene mucho futuro, por lo que las } \\
\text { agencias deberían apostar por esta herramienta y por el canal online" }\end{array}$ \\
\hline E4 & $\begin{array}{c}\text { "Las agencias, sobre todo las offline, tienen que entrar en el negocio de la afiliación } \\
\text { y en el canal online para intentar sobrevivir" }\end{array}$ \\
\hline E5 & $\begin{array}{c}\text { "Todo el que quiera vender en el sector de los viajes debería hacer afiliación, como } \\
\text { foco de negocio y oportunidad" }\end{array}$ \\
\hline$E 6$ & "Seguiremos con un desarrollo conjunto" \\
\hline$E 7$ & $\begin{array}{l}\text { "La relación seguirá existiendo, aunque hay voces que dicen que muchos } \\
\text { anunciantes harán afiliación directa, sin plataformas" }\end{array}$ \\
\hline$E 8$ & $\begin{array}{l}\text { "La relación de futuro será larga y prolongada, ya que se trata de una } \\
\text { herramienta que se adapta perfectamente al producto turístico" }\end{array}$ \\
\hline
\end{tabular}

Fuente: Elaboración propia 


\section{Cuadro 19: Resultados entrevistas}

\begin{tabular}{|c|c|}
\hline $\begin{array}{c}\text { Entrevistado: } \\
\text { Panel de expertos }\end{array}$ & $\begin{array}{c}\text { Relación futura entre el marketing de afiliación y las empresas de } \\
\text { intermediación turística españolas. }\end{array}$ \\
\hline $\boldsymbol{E 9}$ & "Su relación será mucho más fuerte" \\
\hline $\boldsymbol{E 1 0}$ & "La relación seguirá creciendo con un esquema muy sencillo. Win to win" \\
\hline $\boldsymbol{E 1 1}$ & "Dependerá de la legislación" \\
\hline $\boldsymbol{E 1 2}$ & $\begin{array}{c}\text { "Aunque en su inicio se vio como una amenaza, las agencias pueden utilizarlo } \\
\text { como una buena estrategia para su reconversión y fidelizar al cliente" }\end{array}$ \\
\hline $\boldsymbol{E 1 3}$ & $\begin{array}{c}\text { "Muy compleja. Los programas de afiliación deben cambiar y las agencias deben } \\
\text { aportar valor" }\end{array}$ \\
\hline $\boldsymbol{E 1 4}$ & $\begin{array}{c}\text { "Espero que muy buena, nunca hay que sentirse agredido sino buscar las maneras } \\
\text { de colaborar y ver dónde podemos encajar" }\end{array}$ \\
\hline $\boldsymbol{E 1 5}$ & $\begin{array}{c}\text { "En un contexto de crisis como el actual, el marketing de afiliación tiene una } \\
\text { ventaja añadida al permitir un control más riguroso sobre el presupuesto de las } \\
\text { agencias, pagando sólo por resultados obtenidos, por eso su relación de futuro es } \\
\text { prometedora" }\end{array}$ \\
\hline
\end{tabular}

Fuente: Elaboración propia

\section{Cuadro 20: Resultados entrevistas}

\begin{tabular}{|c|c|}
\hline $\begin{array}{l}\text { Entrevistados: } \\
\text { Agencias } \\
\text { mayoristas }\end{array}$ & $\begin{array}{c}\text { Relación futura entre el marketing de afiliación y las empresas de } \\
\text { intermediación turistica españolas. }\end{array}$ \\
\hline E16 & "Mayor conexión, mayor unión, diversificación de productos..." \\
\hline$E 17$ & "Trabajarán codo a codo" \\
\hline$E 18$ & "La cooperación será más estrecha” \\
\hline E19 & $\begin{array}{c}\text { "Las agencias y el marketing de afiliación tienen un largo futuro juntos, ya que es } \\
\text { uno de los pocos mecanismos que permiten controlar la inversión de marketing y } \\
\text { gestionarla mediante objetivos" }\end{array}$ \\
\hline$E 20$ & $\begin{array}{l}\text { "En un plazo no muy lejano, será tan importante para nosotros como fue la } \\
\text { agencia de publicidad, el departamento comercial o tener una web corporativa." }\end{array}$ \\
\hline
\end{tabular}

Fuente: Elaboración propia

\section{Cuadro 21: Resultados entrevistas}

\begin{tabular}{|c|c|}
\hline $\begin{array}{c}\text { Entrevistados: } \\
\text { Agencias } \\
\text { minoristas }\end{array}$ & $\begin{array}{c}\text { Relación futura entre el marketing de afiliación y las empresas de } \\
\text { intermediación turística españolas. }\end{array}$ \\
\hline$E 21$ & $\begin{array}{l}\text { "Creo que convivirán todas las herramientas, pues cuantos más medios tengamos, } \\
\text { mejor servicio daremos a nuestros clientes" }\end{array}$ \\
\hline$E 22$ & $\begin{array}{c}\text { "Si en esa relación de futuro el beneficio de las agencias está asegurado auguro un } \\
\text { futuro prometedor." }\end{array}$ \\
\hline$E 23$ & $\begin{array}{l}\text { "Nuestro mercado, como todos, se basará cada vez más en alcanzar a un mayor } \\
\text { número de personas y permitir la interactuación de las partes. La tecnología } 3.0 \\
\text { con el apoyo de la afiliación será fundamental para el desarrollo de las agencias, } \\
\text { sobre todo de las más pequeñas." }\end{array}$ \\
\hline$E 24$ & "Una relación de unión" \\
\hline$E 25$ & $\begin{array}{c}\text { "No creo que sea posible, sigo reiterándome en que no solemos cooperar, aunque } \\
\text { creo que lo deberíamos de hacer" }\end{array}$ \\
\hline
\end{tabular}

Fuente: Elaboración propia 


\section{Cuadro 22: Resultados entrevistas}

\begin{tabular}{|c|c|}
\hline $\begin{array}{c}\text { Entrevistados: } \\
\text { Agencias online }\end{array}$ & $\begin{array}{c}\text { Relación futura entre el marketing de afiliación y las empresas de } \\
\text { intermediación turistica españolas. }\end{array}$ \\
\hline E26 & "Será una relación muy estrecha. La tendencia del mercado así lo indica" \\
\hline $\mathbf{E 2 7}$ & "No habrá un desarrollo de uno al margen del otro" \\
\hline $\mathbf{E 2 8}$ & $\begin{array}{c}\text { "Será una relación directa sobre todo entre las online y el marketing de afiliación. } \\
\text { Las offline tienden a desaparecer a menos que aporten un valor añadido" }\end{array}$ \\
\hline $\mathbf{E 2 9}$ & $\begin{array}{c}\text { "Esta disciplina del marketing online representa un porcentaje considerable } \\
\text { dentro de las conversiones del sector de viajes. Cualquier empresa, jamás podrá } \\
\text { llegar a tener por sí sola el grado de repercusión que tienen millones de páginas } \\
\text { distribuidoras" }\end{array}$ \\
\hline $\mathbf{E 3 0}$ & "Cada vez más estrecha" \\
\hline
\end{tabular}

Fuente: Elaboración propia

Las opiniones aportadas por los entrevistados en relación a la necesidad futura de emplear herramientas online, como el marketing de afiliación, por parte de las empresas de intermediación turística españolas, son unísonas.

Tal y como se explicita en el marco teórico y según los datos ofrecidos por la CMT, (2012) cada vez se vende más a través del canal online, y los viajes son uno de los productos con más éxito.

Los resultados de las entrevistas precisan que la relación entre el marketing de afiliación y las empresas de intermediación turística españolas será fuerte, duradera, larga y prolongada, toda vez que ambas variables están abocadas a entenderse.

Se trata de un modelo con futuro tanto para las agencias online, como para las offline, puesto que ambos modelos de empresa persiguen los mismos objetivos: aumentar su visibilidad o su rentabilidad, lo que a tenor de los resultados obtenidos, el marketing de afiliación puede facilitar.

En este sentido, y a la vista de los resultados se puede constatar que la Hipótesis III se acepta.

\section{Conclusiones}

El turbulento e incierto escenario económico acaecido en el último lustro (2008-2012) ha provocado una ligera contracción de la demanda turística, lo cual ha contribuido a que los grupos turísticos españoles más importantes realicen grandes esfuerzos para reducir costes en la misma proporción que la caída de los ingresos, con el objetivo de mantener el nivel de beneficios de 2008 aunque a costa de poner en riesgo su propia rentabilidad.

Son ejemplos de esta situación Orizonia que cerraba sus puertas a principio de 2013 o Viajes Barceló, Viajes el Corte Inglés o Globalia Corporación que han tenido que acogerse a un ERTE (Expediente de Regulación de Empleo Temporal) para minimizar esta coyuntura.

Ante este escenario, los esfuerzos del sector turístico se orientan hacia el desarrollo de diferentes estrategias tendentes a ayudar a las empresas y, en concreto a las agencias de viajes, a ser más competitivas en el mercado, al tiempo de facilitarles trabajar de manera más eficiente en la cadena de valor y con ello generar más ingresos y rentabilidad.

Para ello, las agencias de viajes han de ofrecer a sus usuarios una nueva forma de interactuar, de colaborar y de compartir información lo que puede ser facilitado, con mayor eficiencia, por las TICs. Con Internet todos los implicados en el proceso de venta pueden conectarse, colaborar y gestionar negocios de una manera mucho más directa y personal de lo que las técnicas de comunicación comercial convencionales posibilitaban hasta ahora.

Además, la profusión de información que ofrece este canal facilita a la fuerza de ventas de las empresas y a los clientes, tanto reales como potenciales, la oportunidad de adquirir ideas importantes para vender y comprar.

En el ámbito de las empresas de intermediación turística, la amalgama de estas tendencias con la tecnología, ha transformado el proceso de venta, ya que se ha pasado de una "actividad personalizada" a un "proceso interactivo", en el que la relación con el cliente, la comercialización de los productos y la organización de las fuerzas de venta han cambiado de forma decisiva. 
Esta situación conduce a pensar que cada vez es más necesario poner en práctica estrategias de marketing online y herramientas que permitan a las agencias de viajes llegar al cliente de forma más eficiente a través de los nuevos formatos de comunicación y publicidad como puede ser el marketing de afiliación.

A modo de coda, cabe señalar que al contrastar las hipótesis se evidencian los siguientes resultados:

Las empresas de intermediación turística españolas se decantan por implementar el marketing de afiliación de forma progresiva ya que han corroborado que: sólo se paga por resultados generados; ofrece gran capacidad de segmentación; permite optimizar; controla el gasto publicitario en tiempo real o proporciona una alta capacidad de medición y métricas, entre otras bondades; se antoja necesario un proceso de adaptación que elimine el freno a la implementación de nuevas herramientas sobre las que no hay aún muchas experiencias, aunque las existentes se perciben como positivas.

La importancia y repercusión del marketing de afiliación para las empresas de intermediación turística españolas offline no es similar a las online; ya que el negocio tradicional no se adecúa en la misma medida que el online: por su desarrollo tecnológico, por su desconocimiento o por la carencia de una base de datos eficiente.

Las empresas de intermediación turística españolas están abocadas a utilizar herramientas online, como el marketing de afiliación, ya que han percibido que las posibilidades de crecimiento que aporta esta estrategia en el ámbito empresarial son importantes, al revertir de forma considerable en el ahorro de costes y comercialización de sus productos.

\section{Bibliografía}

Albert, I

1999 Gestión, productos y servicios de las agencias de viajes, Colección de Estudios Turísticos. Editorial Centro de Estudios Ramón Areces. Madrid.

Albert, I.

2006 Las agencias de viajes ante la sociedad de la información. Evolución y adaptación al nuevo entorno social. Tesis Doctoral. Universidad Pontificia de Salamanca.

Alza, M.E.

2004 Las nuevas tecnologías de la información y la comunicación. El caso de las agencias de viajes en

Argentina. Tesis de Grado. Universidad Nacional de la Plata.

2004

Andreu, L., Currás, R. y Sánchez I.

2009 "Segmentación de las agencias de viajes en función de la adopción de las TIC." Papers de turisme, 45, 7-20.

Berné, C., García, M., García, M.E.

2011 "La influencia de las TIC en la estructura del sistema de distribución turístico." Cuadernos de Turismo 28.28, 9-22.

Berné, C., García, M., García, M. E., y Múgica, J. M.

2012. "Modelización de los cambios en el sistema de distribución del sector turístico debidos a la incorporación de las tecnologías". Cuadernos de Economía y Dirección de la Empresa, 15(3), 117-129.

Bitner, M. J. y Booms, B. H.

1982 "Trends in travel and tourism marketing: The changing structure of distribution channels". Journal of travel research, 20(4), 39-44.

Brown, B.

2009 The Complete Guide to Affiliate Márketing on the Web: How to Use and Profit from Affiliate Márketing Programs. Atlantic Publishing Company. Ocala. Estados Unidos

Bruner, R.E. et al

2001 Net results.2: best practices for web marketing. New Riders Publishing. Indianapolis

Buhalis, D.

1998 "Strategic use of information technologies in the tourism industry". Tourism Management, 19

(5). 409-421.

Buhalis, D.

2000 "Tourism and information technologies. Past, present and future". Tourisme Management, 25

(1). 41-58. 
Del Alcázar, B.

2002 Los canales de distribución en el sector turístico. Madrid: Esic.

Delgado, J.M., y Gutiérrez, J.

1994 Metodología de las ciencias del comportamiento: Métodos y técnicas cualitativas de investigación en ciencias sociales. Síntesis Psicología. Madrid

De la Rosa, J.M.

2011 "El número de agencias IATA cae un 22\% en dos años". (En línea). Hosteltur.com. Disponible en la Web www.hosteltur.com.

Doolin, B. et al.

2002 "Evaluating the use of the web for tourism marketing: A case study from New Zealand". Tourism Management, 23. 557-561.

ESOMAR

1973 Fieeldwork, Sampling and Questionnaire Desing. Amsterdam. En García, M. (2000), "La observación científica y la obtención de datos sociológicos" en El análisis de la realidad social. Métodos y técnicas de investigación. $3^{\text {a }}$ Edición. 167-201.

Esteban, C.

2003 La calidad de los servicios de intermediación turística: una aplicación empírica a las AVV de la CAM para el segmento de los viajes de ocio. Tesis Doctoral. Universidad Autónoma de Madrid.

Fraiz, J.A., et al

2012 "Las Agencias de Viajes ante la influencia de las redes sociales en el turismo. El caso de Ourense". Libro de actas Congreso AECIT. O Caballiño. 606-611

Galhanone, R. F., Marques, J. A., Toledo, G. L., y Mazzon, J. A.

2010 "Turismo de lujo e Internet. Oportunidades para las agencias de viajes". Estudios y Perspectivas en Turismo, 19, 888-908.

Garrido, $\mathrm{P}$.

2010 Agencias de viajes online: Situación y perspectivas en el comercio electrónico español. Tesis doctoral. Universidad Complutense de Madrid.

Goeldner, C. R. y Ritchie, J. B.

2009 Tourism: Principles, practices, philosophies. Wiley.

Goldschmidt, $\mathrm{S}$ et al

2003 Strategic Affiliate Márketing, Edward Elgar Publishing. Gran Bretaña.

Grande, I. y Abascal, E.

2011 Fundamentos y técnicas de investigación comercial, 11ª Edición, ESIC, Madrid.

Guijarro, M.

2010 Estudio de la literatura y modelos de negocio de la implantación de CRM-modelo cliente céntrico-como enfoque estratégico condicionante de la ventaja competitiva en la pyme: estudio empírico de la aplicación de un CRM-Modelo cliente céntrico-en agencias de viajes. Tesis Doctoral. Universidad Politécnica de Valencia.

Interactive Advertising Bureau Spain (IAB)

2010 Libro Blanco. SEO: Optimización de Webs para Buscadores. (En línea). Cuadernos de comunicación Interactiva. Revista de comunicación Interactiva y el Marketing Digital. 11. Ed. Edipo. Madrid. Disponible en la Webwww.iabspain.net.

Jafari J

2005 "El turismo como disciplina científica". The Scientification of tourism. Politica y Sociedad,. 42, (1). 39-56.

Kendall, K. W. y Booms, B. H.

1989 "Consumer perceptions of travel agencies: Communications, images, needs, and expectations". Journal of Travel Research, 27(4), 29-37.

Kirkpatric, S. A. y Locke, E. A.

1992 "The Development of Measures of Faculty Scholarship", Group and Organization Management, 17. 5-23. Citado en Fernández, J. C., Suárez, M. G., y Roche, I. C. (2001). "Valoración y preferencia de las revistas académicas en el área de marketing: una aplicación del análisis conjunto". Información Comercial Española, ICE: Revista de Economía, (795), 155-178.

López F.

2001 Factores condicionantes de la ventaja competitiva y de los resultados de las Agencias de Viajes en España. Un estudio empírico de sus aspectos estratégicos más relevantes. Tesis Doctoral. Universidad Autónoma de Barcelona. 
Middelton, V.

1997 Marketing in travel and tourism Butterworth Heinemann, Oxford.

Millán, A.

2001 Análisis de la satisfacción de los usuarios con los servicios de las AAVV: concepción, evaluación e

implicaciones empresariales. Tesis Doctoral. Universidad de Castilla La Mancha

Moreno, S. y Aguiar, T.

2006 "Diagnóstico, tendencias y estrategias de futuro para las agencias de viajes. El caso del sector español". Estudios y perspectivas en turismo, 15, 327-349.

Parra, E., Melchior, M., y Ramos A.

2003 "Análisis e impacto de los touroperadores y las agencias de viaje en el transporte turístico: nuevas tendencias en Canarias." Revista de Turismo y Patrimonio Cultural (PASOS), 1 (2), 217-229.

Rastrollo, M.A., y Alarcón, P.

2000 "The competitiveness of tradicional tourist destinations in the information economy" en Reinares,

P. y Calvo, S. (1999): Gestión de la comunicación comercial. McGraw-Hill. Madrid.

Rodríguez del Bosque, I, San Martín, H. y Collado, J.

2005 "El proceso de elección de una agencia de viajes: análisis comparativo según las características sociodemográficas y comportamentales de los usuarios". Cuadernos de Economía y Dirección de la Empresa, (24), 83-104.

Sarabia, F., et al.

1999 Metodología para la investigación en marketing ydirección de empresas. Ed. Pirámide. Madrid.

Sheldon et al.

2001 "What is satisfying about satisfying events? Testing 10 candidate psychological needs". Journal of Personality \& Social Psycology. Vol. 80, Harper, Nueva York

Silverstein, B.

2001 "Developing Internet Partnerships". Direct Marketing. 63(11), 33-43.

Sousa, R.S.

2003 Análisis de la creación de valor en las AAVV en España. Tesis Doctoral. Universidad Complutense de Madrid.

Suárez, L.

2004 El marketing de relaciones como fuente de ventaja competitiva en el sector turístico: una aplicación a las AAVV minoristas. Tesis Doctoral. Universidad de Oviedo.

Suárez, L., Vázquez R. Díaz A.

2004 "El marketing de relaciones y las nuevas tecnologías de la información y la comunicación: análisis del caso de las agencias de viajes minoristas". Ponencia. XVI Encuentro de Profesores

Uiversitarios de Marketing. Alicante, 22, 23 y 24 de Septiembre de 2004.

Suárez, L., Vázquez R., Díaz A.M.

2007 "La confianza y el compromiso como determinantes de la lealtad. Una aplicación a las relaciones de las agencias de viajes minoristas con sus clientes. El comportamiento de la empresa ante entornos dinámicos. XIX Congreso anual y XV Congreso Hispano Francés de AEDEM. Vol 1, 2007, p.6.

Taylor, S.J., y Bogdan R.

1992, Introducción a los métodos cualitativos de investigación. Paidós Básica.

Trespalacios, J. A., Vázquez, R. y Bello, L.

2005 Investigación de Mercados, Métodos de recogida y análisis de la información para la toma de decisiones en marketing, Thomson, Madrid.

Valdivielso, J.L.

2010 Retos del Marketing de Resultados en 2010. OMExpo Madrid

Vellas, F. y Becherel, L.

1999 Comercialización internacional de los viajes y el turismo: un enfoque estratégico. Macmillan Press. Ltd Wardell, DJ.

1998 "El impacto de la distribución en agencias de viajes". Viajes y Turismo. (2). 41-55

Werthner, H. y Klein, S.

1999, Information, thecnology and tourism. A challenging relationship, Wien, Austria: Spiringuer-Verlag. 


\section{Bibliografia}

Comisión del Mercado de las Telecomunicaciones (CMT)

2012. "Informe sobre el Comercio Electrónico en España a través de entidades de medios de pago" (III

Trimestre 2012). (En línea).Se puede descargar en http://www.cmt.es

Estudio General de Internet (EGI)

2006. "Estudio de mercado de Comercio Electrónico (Investigación de los compradores online)". Estudio patrocinado por Colectivos de Compras. Se puede consultar en http://www.estudiogeneraldeinternet.com Johnson, C. y Glasgow, R.

2011. "European Affiliate Marketing Landscape Report". (En línea). Affiliates4u.com \& Webgains. Se puede descargar en http://bit.ly/kunSkM

Globalia Corporación Empresarial, S.A.

2012. "Informe anual".

Grupo Barceló

2012. "Informe anual"

Hosteltur

2012. "Tendencias del sector turístico 2012 marketing y estrategia turística". (En línea). Hosteltur.com.

Disponible en www.hosteltur.com.

Hosteltur

2012. "Ranking Hosteltur de facturación de agencias de viajes online". (En línea). Hosteltur.com.

Disponible en www.hosteltur.com.

Instituto de Estudios Turísticos (IET)

2008. "Encuesta de movimientos turísticos en fronteras (FRONTUR).Informe anual 2008". Ministerio de Industria, Turismo y Comercio.

Instituto de Estudios Turísticos (IET)

2009. "Encuesta de movimientos turísticos en fronteras (FRONTUR).Informe anual 2009". Ministerio de Industria, Turismo y Comercio.

Instituto de Estudios Turísticos (IET)

2010. "Encuesta de movimientos turísticos en fronteras (FRONTUR).Informe anual 2008". Ministerio de Industria, Turismo y Comercio.

Instituto de Estudios Turísticos (IET)

2010. "Encuesta de movimientos turísticos de los españoles (FAMILITUR). Informe anual 2010". Ministerio de Industria, Turismo y Comercio.

Instituto de Estudios Turísticos (IET)

2010. "Encuesta de gasto turístico (EGATUR), 2010". Ministerio de Industria, Turismo y Comercio.

Instituto de Estudios Turísticos (IET)

2011. "Encuesta de movimientos en fronteras (FRONTUR). Informe septiembre 2011". Ministerio de Industria, Turismo y Comercio.

Instituto de Estudios Turísticos (IET)

2011. "Encuesta de movimientos turísticos de los españoles (FAMILITUR). Informe septiembre 2011". Ministerio de Industria, Turismo y Comercio.

Instituto de Estudios Turísticos (IET)

2011. "Encuesta de gasto turístico (EGATUR), septiembre 2011”.Ministerio de Industria, Turismo y Comercio.

Ministerio de Trabajo e Inmigración

2012. "Encuesta de coyuntura laboral". Subdirección General de Estadística del Ministerio de Trabajo e Inmigración. España.

Nexotur

2011. "Ranking NEXOTUR de Minoristas de Viajes". Nexotur. Periódico Profesional de la Nueva Agencia de Viajes. Madrid, España.

Nexotur

2012. "Ranking NEXOTUR de Mayoristas de Viajes". Nexotur. Periódico Profesional de la Nueva Agencia de Viajes. Madrid, España.

Nexotur

2013. "Globalia pierde $17 \mathrm{M} €$ en 2012 "por el alto precio del combustible y el conflicto con los pilotos". Nexotur. Periódico Profesional de la Nueva Agencia de Viajes. Madrid, España. 


\section{Notas}

1 Intermediación Turística: autores como Alcázar (2002), establecen que la tipología de intermediarios que constituyen el sistema de distribución en el sector turístico en España está configurado por los siguientes elementos: agencias de viajes (mayoristas, minoristas y mayoristas-minoristas); sistemas centralizados de reservas (GDS y Centrales de reservas) y otros intermediarios (brokers turísticos). En este artículo y en relación a dicha clasificación, al hablar de intermediación turística, sólo se consideran como ámbito de, las agencias de viajes tradicionales y las agencias online; siendo conscientes de que el concepto intermediación es mucho más amplio.

2 Estudio General de Internet: recopila una exhaustiva información sobre los hábitos y costumbres de los internautas españoles a través de millones de impactos publicitarios en banners, webs colaboradoras y artículos de prensa.

3 IATA: Asociación de Transporte Aéreo Internacional.

4 Dato a septiembre de 2011.

5 Esta Ley fue derogada por el Real Decreto Legislativo 1/2007, de 16 de noviembre, publicado en el BOE de 30 de noviembre y con entrada en vigor el 1 de diciembre. Los viajes combinados se encuentran regulados en el Libro Cuarto.

6 Halcón Viajes Ecuador era la división minorista del grupo Globalia. Formada por la unión de Halcón Viajes, consolidada como líder del sector turístico español en 2011 en relación al número de puntos de ventas y creación de productos exclusivos y por Viajes Ecuador que fue adquirida por el grupo en 2003 como una de las agencias de mayor proyección por su fuerte presencia en todo el territorio español (Globalia, 2012).

7 Barceló Viajes es la división minorista del Grupo Barceló. En 2011 consolidaba su reconocimiento como "la marca de los viajeros", por parte del consumidor turístico. Durante ese año la marca afianzaba su protagonismo y relevancia gracias a la implementación de estrategias, iniciativas y herramientas que la habían situado como una de las empresas líderes del sector. En medio de un escenario macroeconómico negativo, la cifra de negocios en 2011 experimentaba un crecimiento global de un $8 \%$ respecto a 2010, hasta alcanzar los 521 millones de $€$ (Barceló, 2012).

8 Programas de afiliación: pueden estar gestionados de forma directa o indirecta a través de las plataformas de afiliación. Sus funciones radican en prestar servicios de traking de resultados; optimización de los sites; ejercer el control de fraude; realizar estudios de mercado; seleccionar los publishers más adecuados, fomentar la búsqueda activa u optimizar las campañas en tiempo real.

9 Viajes El Corte Inglés es cliente en España de la Plataforma de Afiliación Affilinet.

10 Barceló Viajes es cliente en España de la Plataforma de Afiliación Zanox. 